\title{
SOLIDARIEDADE ACADÊMICA E EDIÇÃO DE PERIÓDICOS CIENTÍFICOS
}

\author{
Silvânia Siebert ${ }^{*}$ \\ Maria Marta Furlanetto* \\ Universidade do Sul de Santa Catarina \\ Programa de Pós-Graduação em Ciências da Linguagem \\ Tubarão, SC, Brasil
}

Publicamos mais uma edição de nossa revista Linguagem em (Dis)curso. Para os editores, compartilhar mais um número da Linguagem em (Dis)curso com os leitores é uma imensa satisfação. A satisfação é motivada, em boa parte, pela solidadriedade acadêmica de nossos consultores, que leem, releem, analisam, avaliam e tecem pareceres para os artigos submetidos. Sem a participação solidária destes pesquisadores, a publicação e a circulação de conhecimento científico especializado ficariam comprometidas. E não nos referimos apenas à LemD: temos conhecimento de que muitas outras revistas científicas compõem um rol.

Temos desenvolvido, de 2017 para cá, no planejamento de nossa revista, o que chamamos de episódios, focalizando, simultaneamente aos temas publicados, tópicos que sobrevoam os eventos de espaço-tempo acompanhando os rumos do trabalho científico e suas implicações de caráter administrativo, político, histórico e social. Pretendemos, com esta direção, fornecer interpretações e abertura para o esforço de produzir trabalho editorial na supervisão de produção e circulação do conhecimento. Em números anteriores abordamos assuntos como plágio, autoria, produtivismo, entre outros. Nesta edição discutimos a relação necessária entre solidariedade, cooperação e divulgação científica.

O tema envolve uma prática de trabalho das revistas científicas especializadas que adotam, como um dos procedimentos de avaliação para a publicação de texto submetido, a leitura às cegas, feita por consultores - a maioria, professores pesquisadores ligados a Programas de Pós-Graduação, que realizam o referido trabalho de forma solidária: sem remuneração, como prática de colaboração científica. Aspectos objetivos e subjetivos acompanham o processo de produção de uma revista especializada que tem como propósito a publicação de textos originais e inéditos oriundos de pesquisas realizadas na área de Letras e Linguística, em especial, nesta revista, sobre texto e discurso. A tarefa não é fácil, e requisita alto grau de responsabilidade.

\footnotetext{
* Doutora em Linguística Aplicada pela Universidade Estadual de Campinas. Docente do Programa de Pósgraduação em Ciências da Linguagem da Universidade do Sul de Santa Catarina. Editora de Linguagem em (Dis)curso. E-mail: silvania@cinemaistv.com.br. ORCID: https://orcid.org/0000-0002-7852-0968.

** Doutora em Linguística Aplicada pela Université Paris VIII. Docente do Programa de Pós-graduação em Ciências da Linguagem da Universidade do Sul de Santa Catarina. Editora de Linguagem em (Dis)curso. E-mail: mmartafurlanetto@gmail.com. ORCID: http://orcid.org/0000-0002-0298-765X.
} 
De um lado temos as avaliações predominantemente quantitativas da produção acadêmica, que pressionam para obter cada vez mais textos publicados; de outro, o aumento de submissões exige, para as várias especialidades, mais consultores, mais avaliadores solidários. As revistas especializadas precisam contar com esta participação. No entanto, este fazer exige tempo substancial, concentração e busca para verificação (de dados, conceitos, noções), bem como para propor sugestões e recomendações adequadas, que efetivamente auxiliem no aperfeiçoamento de textos com mérito. Isso representa dias dedicados ao trabalho - um trabalho especializado de que não se pode abrir mão.

\section{A SOLIDARIEDADE}

Em nosso percurso de leitura e pesquisa, vimos que a solidariedade é um tema a que a sociologia dedica atenção desde sua constituição como ciência no século XIX. Está presente no trabalho de Émile Durkheim. O sociólogo considerava que "só pode haver solidariedade entre outrem e nós se a imagem desse outrem se unir a nós" (DURKHEIM, p. 28). Completa:

Onde existe a solidariedade social, apesar do seu caráter imaterial, ela não permanece no estado de pura potencialidade, mas manifesta sua presença através de efeitos sensíveis. Onde é forte, inclina fortemente os homens uns para os outros, coloca-os frequentemente em contato, multiplica as ocasiões que tem que se relacionar (p. 31).

Pensar em solidariedade envolveria o outro como condição de existência, envolveria uma projeção imaginária de nós no outro - nos reconhecermos nesse outro. Para os estudos discursivos, a inter-relação eu/outro é constitutiva da língua. Em uma relacão direta, poderíamos considerar a solidariedade, nos termos de inter-relação, como condição de existência da linguagem - e da própria humanidade.

Podemos retornar, neste ponto, em visão contemporânea, às considerações sobre a noção de imaginário na sociologia compreensiva de Michel Maffesoli (2001). Imaginário diz respeito a estado de espírito de um povo, de um agrupamento social, componto uma matriz espiritual coletiva, que se destaca de nossa compreensão naturalizada de individualismo, que ressoa ilusoriamente em nós como bem-estar pessoal num mundo racional, porém implicando competição, busca de superioridade, reconhecimento e fama - e provavelmente, como consequência, isolamento e solidão.

O IN-divíduo é, afinal, dividido desde sempre: o imaginário humano envolve substancialmente imaginação, sonhos, futuridade, afetividade, fantasia, jogo, ficção, utopia, atuando como laço social, que é cimento para criar relações. Relação implica interação e partilha, percepção de que a alteridade é fundamento da humanidade, e que a linguagem é seu material de relacionamento e comunicação. Assim é que Maffesoli (como tantos outros estudiosos da sociedade) percebe indivíduo como uma noção superada:

\footnotetext{
O termo indivíduo, já o disse, parece-me superado, ao menos no sentido estrito. Talvez se deva falar, quanto à pós-modernidade, em uma persona que desempenha diversos papéis nas tribos às quais adere. A identidade fragiliza-se. As diferentes identificações, em contrapartida, multiplicam-se.

As grandes reuniões musicais, esportivas, consumistas, demonstram isso. Em cada um desses casos, trata-se de se perder no outro. (MAFFESOLI, 1998, p. 12)
} 
Em Análise de Discurso o texto é tomado como espaço de possibilidades relacionais (ORLANDI; LAGAZZI-RODRIGUES, 2006). Como unidade de análise materializaria o dizer do autor para o leitor, por exemplo. Porque sem o encontro com o outro o texto não completaria sua circularidade: precisa alcançar outrem para fazer sentido, ser interpretado. Sem o outro, haveria o vazio. As projeções imaginárias, do eu e do outro, apareceriam como um amálgama para o funcionamento dos sentidos entre os sujeitos; a cooperação e a solidariedade participariam como a força motriz do fluxo discursivo, como implusionador do estar com o outro. Se ver no outro. Formar o laço social.

É para não perder ou desagregar o laço social - que conduz a justificar a solidariedade - que nos permitimos, não raramente, utilizar o que Maffesoli denominou liberdades intersticiais (MAFFESOLI, 1993), que são "pequenas utopias intersticiais" para conservação dos grupos - formas de escapar às pressões excessivas do mundo normalizado, pequenos arranjos que ajudam a reduzir a ansiedade e o estresse, sem a pretensão, nesse nível, de produzir uma revolução. São, contudo, índice de resistência a qualquer projeto maior de manipulação. Essas formas triviais de autolibertação, contudo, podem perigosamente romper o limite do aceitável, do ético, no esforço astucioso de responder a pressões (como a de publicar, por exemplo) e ao mesmo tempo não satisfazer requisitos (originalidade, ineditismo).

O sociólogo destaca a noção de comunicação como encontro para compreender. Compreender, etimologicamente, corresponde a: "pegar com, tomar junto, reunir, abordar o mundo na sua totalidade, abrir-se aos outros." (MAFFESOLI, 2003, p. 14). Isso implica vínculos emocionais, implica solidariedade em todos os níveis. Aqui, trata-se de solidariedade no mundo acadêmico.

\section{SOBRE SOLIDARIEDADE E PRODUTIVISMO}

No artigo O produtivismo acadêmico e seus impactos na pós-graduação stricto sensu: uma ameaça à solidariedade entre pares?, os autores se interrogam quanto o produtivismo ameaça a solidariedade acadêmica. Para tanto, buscam fundamentar a noção de solidariedade, e a definem "como um conjunto de relações cooperativas que visam consolidar uma totalidade, torná-la coesa, sólida.". A partir daí, veem a solidariedade acadêmica como "um conjunto de relações cooperativas no âmbito das universidades que promovem a coesão da academia, ou seja, a consolidação de uma rede de colaboração voluntária que dá sustentação ao fazer acadêmico." (PATRUS; DANTAS; SHIGAKI, 2015 , p.14). Eles assumem que a revisão por pares é um mecanismo exemplar da solidariedade acadêmica, visto ser uma atividade voluntária.

Os autores associam cooperação e solidariedade para mostrar uma distinção necessária: a cooperação é componente da solidariedade, mas pode haver cooperação sem solidariedade, uma vez que aquela tem caráter mais pragmático ou utilitarista. Em qualquer instituição a colaboração (laborar com, co-operar) de seus componentes é imprescindível para realizar metas de planejamento; a solidariedade implica mais que isso. Podemos compreender que ela exige, como explicitado por Maffesoli, vínculos emocionais, uma abertura para os outros, um trabalho em que a individualidade não seja 
o elemento privilegiado, porque a solidariedade tem um caráter comunitário, como explicam Patrus, Dantas e Shigaki (2015, p. 14); portanto, envolve a compreensão de que um imaginário funciona como cimento para que a comunidade em questão funcione voluntariamente em harmonia para a consecução das tarefas pertinentes - sem o que todos perdem algo em algum sentido.

O produtivismo (como o temos compreendido na academia), dizem os autores, "tende a corroer a noção de pertinência a esse sistema [a pós-graduação]" (p. 14). É como dizer que o que deveria ser um corpo docente/grupo de pesquisa com objetivos próprios se estilhaçasse em figuras individuais laborando por interesse próprio - o que fragiliza a coesão. A consolidação de qualquer projeto de grupo estaria ameaçada diuturnamente pelo produtivismo, que se definiria como contraditório para o desenvolvimento do próprio conhecimento nas instituições.

Para Sguissardi, um dos pesquisadores que fundamentam o artigo supracitado, o produtivismo acadêmico "segue a lógica do mercado ou da transformação, no capitalismo atual, de todos os bens materiais e simbólicos em mercadoria, e das universidades e institutos de pesquisa em empresas ou corporações, devendo esses ser geridos nos moldes gerenciais destas" (SGUISSARDI, 2010).

Convém apontar que o produtivismo não se mostra como um fenômeno observável que surge espontaneamente no decurso do tempo (como o crescimento do léxico das línguas) e por miríades de influências mais ou menos perceptíveis - fenômeno que se busca, em certo momento, explicar e registrar. Pelo contrário: a exigência de quantidade para avaliação e controle é datada (anos 1950 nos Estados Unidos) e conhecida pelo mote "publicar ou perecer". Por isso mesmo, produtivismo já é um derivado negativo em contraponto ao termo original, que não deve constar (ao que tudo indica) nos documentos oficiais das agências de fomento e de avaliação; ali se trata de produtividade (volume de produção) - bolsa de produtividade, por exemplo. A forma produtivismo corresponde à interpretação situada de quem vê nessa orientação mais mal que bem, contrapondo qualidade a quantidade. Produtividade (conceito de Economia) é uma medida para estabelecer o que se chama performance de uma empresa, daí que, trasladada para a área científica, significa que os pesquisadores são avaliados por sua performance científica.

Esta discussão nos faz pensar que as revistas especializadas - ao menos as de livre acesso - se contituem em lugares de resistência, lugares de produção onde o capital não é o que determina a publicação.

$\mathrm{Na}$ Linguagem em (Dis)curso temos recebido cada vez mais submissões; para responder a essa demanda, temos solicitado a participação de mais consultores, mais pesquisadores solidários para exercerem a função de avaliadores. Se fundamental para a existência e a persistência dos periódicos especializados, entendemos que esta função não é reconhecida pela área como de importância crucial. Uma vez que a atividade regular de consultor de periódico não recebe pontos - ou não é adequadamente valorada quando é realizado o relatório periódico do Coleta $C A P E S$, por exemplo -, não se pode esperar que os consultores deem continuamente prioridade a tal atividade. Este fator age como uma forte força contrária à solidariedade acadêmica, uma vez que o consultor não é remunerado pela tarefa e também não é reconhecido pelo sistema de avaliação oficial; resta a ele, então, o reconhecimento pelos pares, por participar de um grupo de pertença 
da sociedade acadêmica, e ainda, provavelmente, por estar ele, como pesquisador, submetido à mesma pressão para publicar, esperando também contar com a solidariedade de outrem. Realizar uma avaliação justifica-se pelo forte laço de solidariedade que (ainda) une os pares ao processo de produção e veiculação de ciência realizado pelos periódicos.

Mas até quando teremos de resistir? Até quando teremos de aceitar a condição de consultor como subalterna?

Há um lado irônico no sistema produtivista: se o que conta na avaliação oficial é o que se lê e cita (o que circula no mercado), talvez se faça mais leitura pela necessidade de consultar autores e fazer referências na própria produção que ao buscar conhecimento de forma mais livre. Dado o volume de leitura disponível em todas as áreas e mesmo numa única área de especialidade, somos levados a selecionar obras e artigos, dos quais também vamos selecionar capítulos ou tópicos específicos.

Outro percalço é que o grande volume de material para avaliação também tem redundado em alto percentual de reprovação. Para os consultores, a leitura de trabalhos de baixa qualidade, que provavelmente reprovarão, pode levar à sensação de tempo mal aproveitado.

\section{PUBLICAR OU PERECER}

Em boletim publicado no blog da base Scielo (PLUME; van WEIJEN, 2014), a expressão "publicar ou perecer" é tomada como fator de pressão sobre os pesquisadores, que precisam publicar para se manterem relevantes e bem-sucedidos na comunicade acadêmica. O boletim mostra, por meio de dados quantitativos, que a pesquisa vem aumentando, com maior número de pesquisadores compartilhando publicações, em coautoria. Este dado confirma que a pontuação dada aos autores serve de incentivo à cooperação entre os pares. Mas, por que somente os autores são valorizados? A premissa, que parece funcionar para o sistema, é que a publicação é um fim em si mesma; qualquer espaço serviria para expor o produto - no caso, artigos, ensaios, debates, entre outros. Nesta linha de raciocínio, as revistas especializadas estariam em processo de extinção.

Ainda acreditamos, contudo, que acima do processo quantitavo (estatístico) há o qualitativo: o reconhecimento de que os textos publicados nas revistas especializadas ganharam a atenção de especialistas da área, de que passaram por um crivo de qualidade e relevância científica para chegar até você, leitor. Queremos dizer: o interesse "desinteressado" do consultor que permite publicarmos a cada quatro meses nova edição, exercitando novos saberes, e termos leitores que se interessam pelos temas aqui publicados.

Temos certeza de que o êxito desta publicação subsiste pelo empenho de todos os envolvidos no processo, mas o consultor é pilar nesta estrutura. É ele, sem ser identificado pelo autor, que analisará o texto e dará seu aval, às vezes positivo, outras vezes negativo. Em uma submissão, que tem como critério a avaliação duplo-cega, nem o consultor sabe quem escreveu o texto, nem o autor sabe quem avaliou o texto submetido. É uma tradição das revistas especilizadas, que garantiria para a maioria dos pesquisadores a qualidade, a confiabilidade, a integridade e consistência da literatura acadêmica (NASI-CALÒ, 2015). 
Pelo valor do processo de publicação dado às revistas especializadas que reivindicamos nesta edição, que a solidariedade acadêmica seja valorizada e estimulada, como laço de trabalho que permite a circulação de conhecimento de qualidade e de relevância para toda a comunidade, seja científica ou não.

"Sem a dimensão de solidariedade, o 'publicar ou perecer' pode transformar-se em publicar e perecer.", destacam Patrus, Dantas e Shigaki (2015, p. 14). Isso atingiria não apenas o autor, mas o próprio sistema, uma vez que se perderia a perspectiva comunitária.

\section{REFERÊNCIAS}

DURKHEIM, E. Da divisão do trabalho social. Trad. Eduardo Brandão. São Paulo: Martins Fontes, 1999.

MAFFESOLI, M. Liberdades intersticiais. In: MORIN, E.; BAUDRILLARD, J.: MAFFESOLI, M. $A$ decadência do futuro e a construção do presente. Florianópolis: Ed. da UFSC, 1993.

MAFFESOLI, M. Mediações simbólicas: a imagem como vínculo social. Revista FAMECOS, Porto Alegre, n. 8, p. 7-14, jul. 1998.

MAFFESOLI, M. O imaginário é uma realidade. Revista FAMECOS, Porto Alegre, n. 15, p. 74-82, ago. 2001.

MAFFESOLI, M. A comunicação sem fim (teoria pós-moderna da comunicação). Revista FAMECOS, Porto Alegre, n. 20, p. 13-20, abr. 2003.

NASI-CALÒ, L. Avaliação por pares: prós e contras. Blog Scielo. Março de 2015.

ORLANDI, E. P.; LAGAZZI-RODRIGUES, S. (Org.). Discurso e textualidade. Campinas: Pontes, 2006. PATRUS, R.; DANTAS, D. C.; SHIGAKI, H. B.. O produtivismo acadêmico e seus impactos na pósgraduação stricto sensu: uma ameaça à solidariedade entre pares? Cad. EBAPE.BR, Rio de Janeiro, v. 13, n 1, p. 1-18, jan./mar. 2015.

PLUME, A.; van WEIJEN, D. Publicar ou perecer? O aumento do autor fracionado. Blog Scielo. Outubro 2, 2014. Publicado originalmente na newsletter Elsevier "Research Trends Issue 38".

SGUISSARDI, V. Produtivismo acadêmico. In: OLIVEIRA, D. A.; DUARTE, A.; VIEIRA, L. (Org.). Dicionário de Trabalho, Profissão e Condição Docente. Belo Horizonte: Ed. UFMG, 2010. Disponível em: https://www.gestrado.net.br/?pg=dicionário-verbetes\&id=336 Acesso em: 25 fev. 2019.

Este texto está licenciado com uma Licença Creative Commons Atribuição 4.0 Internacional. 